HUMANIKA Vol. 19 No. 1 (2014) ISSN 1412-9418

Menakar Penegakan Hak Asasi Manusia Di Indonesia

Slamet Subekti

\title{
MENAKAR PENEGAKAN HAK ASASI MANUSIA DI INDONESIA: HASIL SURVEI SKALA LOKAL SAMPAI GLOBAL
}

\author{
Slamet Subekti \\ Fakultas Ilmu Budaya Universitas Diponegoro \\ J1. Prof. H. Soedarto, SH Tembalang Semarang 50275 \\ Email: slametsubekti01@ gmail.com
}

\begin{abstract}
This paper discusses human rights in Indonesia today is based on the results of the locally, nationally and globally surveys. The national and international surveys concluded that the enforcement of human rights in Indonesia in 2013 decreased due to the performance of the institutions of human rights is not optimal, and that the government failed to crack down on violations of human rights. Meanwhile, the survey among students shows positive response to the exercise of the right human rights in civil and political; economic, social and cultural; and solidarity dimensions. The importance of human rights education is to support the development of student character with Indonesian personality, and responsive to the global environment.
\end{abstract}

Keywords: Human Rights in Indonesia, local, national and global survey

\section{PENGantaR}

Paper ini menggambarkan penegakan hak asasi manusia (HAM) di Indonesia dewasa ini. Perspektif difokuskan pada hasil survei tentang kinerja kelembagaan HAM di Indonesia dalam skala nasional sebagaimana dilaporkan oleh SETARA Institute (Desember 2013), dan laporan internasional dari Human Rights Watch (Januari 2014). Sedangkan untuk skala lokal mengacu pada hasil survei yang penulis lakukan pada pertengahan Desember 2013 di kampus Universitas Diponegoro, dengan melibatkan 80 mahasiswa angkatan 2013/2014 Program Studi Pemanfaatan Sumber-daya Perikanan, Fakultas Perikanan dan Ilmu Kelautan.

Penjaringan persepsi responden mahasiswa melalui kuesioner. Kuesioner dirancang dengan memuat 30 pertanyaan kunci, yang mencakup ketiga dimensi HAM: kemerdekaan sipil dan politik;
HAM ekonomi, sosial dan budaya; serta hak-hak kelompok (lihat Lampiran 1). Pengolahan data dilakukan dengan tabulasi persentase. Selanjutnya, hasil survei disajikan dalam pembahasan analisis dan sintesis.

Pembahasan makalah ini dikembangkan dari pertanyaan kunci: Apa dasar konvensi dan dimensi HAM? Bagaimana kinerja kelembagaan HAM di Indonesia menurut survei skala nasional maupun internasional? Bagai-mana situasi mutakhir HAM di Indonesia melalui survei skala lokal sebagai representasi dari persepsi mahasiswa?

\section{KONVENSI DAN DIMENSI HAM}

HAM mengacu pada sejumlah hak yang melekat pada setiap orang, sebagai prasyarat menjadi manusia. HAM diterapkan bagi semua manusia di belahan dunia mana pun tanpa pengecualian, jadi 
bersifat universal. HAM juga melekat pada diri semua orang tanpa memandang ras, agama, jenis kelamin, warna kulit, usia, dan fitur-fitur lain yang membedakan seseorang dengan sesamanya (Barkemeyer dan Kunzi, 2011).

\section{A. Konvensi HAM}

Basis legal HAM mengacu pada ñthe International Bill of Human Rightsò mencakup UN Universal Declaration of Human Rights (1948), kovenan Civil and Political Rights \& Economic Social and Cultural Rights (1966). Kemudian dilengkapi serangkaian konvensi PBB, seperti Konvensi Jeneva berkaitan Status Pengungsi, Konvensi Hak-hak Anak terhadap Penganiayaan, maupun Konvensi PBB tentang Hak-hak Pribadi Berkebutuhan-khusus.

Dalam konteks Indonesia, basis legal HAM selain hukum internasional, juga mengacu pada konstitusi negara UUD RI 1945 beserta Amandemennya, dan UU No. 39 Tahun 1999. Dalam perkembangannya, Pasal 28 UUD 1945 Amandemen telah mengakomodasi berbagai norma HAM internasional diselaraskan dengan latar sosial dan inti budaya Indonesia sebagaimana terumuskan dalam dasar filsafat negara kita Pancasila.

\section{B. Dimensi HAM}

Hak Asasi Manusia lazim dibagi dalam tiga dimensi. Dimensi pertama, hak kemerdekaan sipil dan politik meliputi: hak untuk hidup, larangan perbudakan dan paksaan menjadi buruh, perlindungan dari penyiksanaan, kebe-basan berpikir, beragama, larangan terhadap diskriminasi, dan hak suara (Barkemeyer dan Kunzi, 2011).

Dimensi kedua, HAM ekonomi, sosial dan budaya meliputi: hak mendapatkan pekerjaan dengan penghasilan layak, membentuk serikat pekerja, kesetaraan lelaki dan perempuan, perlindungan anggota keluarga, mendapatkan penghidupan layak dengan kecukupan pangan, standar tinggi atas kesehatan fisik dan mental, hak pendidikan, dan partisipasi dalam kehidupan budaya.

Dimensi ketiga, hak-hak solida-ritas meliputi: hak untuk mengembang-kan diri, mendapatkan lingkungan hidup yang bersih, dan berhak atas perdamaian. Penting dipahami bahwa ketiga dimensi tersebut tidak dapat dipisahkan satu sama lain. Oleh karena itu, tidak boleh satu pun hak yang tercantum dalam suatu dimensi lebih diutamakan daripada hak-hak yang tercantum pada dimensi lainnya.

\section{PELAKSANAAN DAN PE- LANGGARAN HAM}

Pengakuan arti penting HAM diteguhkan dengan terjadinya berbagai kasus pelanggaran HAM. Sementara itu, penegakan HAM mengandaikan dua perspektif, baik pelaksanaan maupun pelanggarannya. Negara dalam posisi bertanggung-jawab untuk melindungi rakyatnya dari tindak pelanggaran HAM, serta berkewajiban untuk menciptakan kondisi yang menjamin rakyat terpenuhi HAM-nya. Pembentukan Komnas HAM, seperti halnya keberadaan lembaga swadaya masyarakat (LSM) berperan penting sebagai watchdog. LSM seperti Amnesty International dan Human Rights Watch bertugas mengamati jalannya pelaksanaan HAM di seluruh dunia.

LSM bidang HAM menaruh perhatian atas pelanggaran yang terjadi, dan melakukan tekanan kepada pemerintah melalui kampanye publik. Bagi negara-negara demokratis menjadi kebutuhan untuk merespon positif evaluasi yang dilaporkan oleh lembaga HAM independen, baik dalam skala lokal, nasional, maupun global. Pada gilirannya, evaluasi tersebut akan ditindak-lanjuti dengan aksi nasional untuk meningkatkan kinerja lembaga-lembaga HAM dengan agenda utama penegakan HAM di negara tersebut. 
HUMANIKA Vol. 19 No. 1 (2014) ISSN 1412-9418

Menakar Penegakan Hak Asasi Manusia Di Indonesia

Slamet Subekti

\section{A. Survei Nasional}

SETARA Institute ÏLSM HAM yang bermarkas di Jakartað untuk keempat kalinya menyelenggarakan survei persepsi untuk mengukur Indeks Kinerja Penegakan HAM di Indonesia. Survei dilakukan pada tanggal 28 November sampai 5 Desember 2013 dengan melibatkan 200 responden di 20 provinsi, yang terdiri dari pegiat HAM, akademisi, dan tokoh masyarakat. Sampel ditetapkan dengan menggunakan metode purposive sampling yang ditetapkan oleh SETARA Institute berdasarkan kriteria tertentu, dan snowballing di mana seorang narasumber dapat menginformasikan narasumber lain yang layak untuk menjadi responden survei ini. Pengumpulan data dilakukan dengan web-based survey, di mana para responden mengisi kuesioner ke website khusus (Hendardi, Naipospos dan Hasani, 2013).

Indeks kinerja HAM Republik Indonesia pada 2013 ini didasarkan pada 8 indikator: (1) penyelesaian pelanggar-an HAM di masa lalu; (2) kebebasan berekspresi; (3) kebebasan berkeyakin-an; (4) rencana aksi nasional HAM dan kinerja lembaga HAM; (5) perlindungan warga Negara; (6) penghapusan hukum-an mati; (7) penghapusan diskriminasi; dan (8) hak atas ekonomi-sosial-budaya. Kinerja penegakan HAM tahun 2013 dinilai menurun (2.52 poin) dibanding-kan tahun 2012 (2.82 poin). Tren penurunan tersebut ditengarai karena kinerja kementerian terkait masih lemah, mereka dianggap tidak mampu me-nyelesaikan kasus HAM secara signifikan (SETARA Institute, 2013).

Kementerian Hukum dan HAM

serta Kementerian Pemberdayaan Perempuan dan Perlindungan Anak masih belum berkontribusi maksimal. Demikian pula, kinerja tiga lembaga yang mendapat mandat khusus dari negara: Komnas HAM, Komnas Perempuan, dan Komisi Perlindungan Anak Indonesia dinilai belum optimal. Masyarakat menganggap kinerja Komnas HAM paling buruk, berhubung konsistensi lembaga tersebut mengalami stagnasi (Mahbub, 2013).

\section{B. Survei Global}

Human Rights Watch (HRW) $\ddot{i}$ LSM HAM internasional yang bermarkas di New Yorkð dalam laporan Januari 2014 menguatkan hasil survei SETARA Institute menyimpulkan bahwa penegakan HAM di Indonesia mengalami kemunduran dibandingkan tahun sebelumnya. HAM menunjukkan sedikit peningkatan pada 2013, Presiden Susilo Bambang Yudhoyono menyam-paikan himbauan publik agar kebebasan beragama dan toleransi lebih besar. Akan tetapi, di lapangan terjadi penyerangan dan pengusiran terhadap kelompok Syiah dan Ahmadiyah, serta maraknya peraturan yang diskriminatif ñmemojokkanò perempuan (Human Rights Watch, 2014).

Pemerintahan Yudhoyono sepanjang tahun lalu dianggap gagal lagi menegakkan hukum yang menjadi hak kalangan minoritas. Sampai saat ini, ratusan orang masih bertahan di lokasi pengungsian karena terusir dari kampungnya akibat perbedaan keyakin-an beragama, seperti penganut Ahmadiyah di Lombok dan penganut Syiah di Sidoarjo. Ada di antara mereka yang tujuh tahun tinggal di barak pengungsian. Kalaupun ada pelaku kekerasan yang diseret ke jalur hukum, biasanya sebatas pelaku lapangan, sedangkan para ñdalangnyaò tidak tersentuh hukum.

Laporan HRW soal nasib perempuan Indonesia juga sulit dibantah. Dalam urusan ini, pemerintah bahkan bisa dianggap aktif melakukan diskriminasi. Catatan dari Komisi Nasional Anti Kekerasan terhadap Perempuan menunjukkan bahwa sampai 2013 terdapat 342 peraturan yang membedakan perlakuan terhadap perempuan dari kaum lelaki, 97 persen di antaranya di daerah, seperti peraturan tentang cara berpakaian, peraturan prostitusi, dan pornografi. Peraturan dan sikap pemerintah dalam berbagai bentuk jelas membahayakan kemajemukan dan kelangsungan hidup bangsa (lihat Tabel 1). 
Tabel 1.

Penegakan HAM di Indonesia Tahun 2013

\begin{tabular}{|c|c|}
\hline Pelaksanaan HAM & Pelanggaran HAM \\
\hline $\begin{array}{l}\text { Presiden SBY menyampaikan himbauan } \\
\text { publik agar kebebasan beragama dan } \\
\text { toleransi lebih besar. }\end{array}$ & $\begin{array}{l}\text { Respon otoritas nasional lemah atas } \\
\text { berkembangnya kekerasan dan diskriminasi } \\
\text { terhadap kelompok agama minoritas. }\end{array}$ \\
\hline $\begin{array}{l}\text { Kebebasan berekspresi melalui diskusi } \\
\text { publik film dokumenter ñThe Act of } \\
\text { Killingò tentang pembantaian yang } \\
\text { dipimpin tentara terhadap antara } 500.000 \\
\text { sampai lebih dari satu juta anggota dan } \\
\text { terduga simpatisan PKI rentang 1965-1966. }\end{array}$ & $\begin{array}{l}\text { Aliansi Jurnalis } \quad \text { Independen } \\
\text { medokumentasi-kan } 23 \text { kasus kekerasan } \\
\text { terhadap jurnalis dalam } 6 \text { bulan pertama } \\
\text { 2013, termasuk penyerangan } 2 \text { wartawan } \\
\text { selama serangan pembakaran kantor } \\
\text { stasiun TVRI Gorontalo. }\end{array}$ \\
\hline $\begin{array}{l}\text { Pilkada di Indonesia dalam beberapa tahun } \\
\text { terakhir memunculkan politisi muda, } \\
\text { termasuk gubernur Joko Widodo, yang } \\
\text { menjanjikan akan memutuskan politik } \\
\text { gaya-patronase tradisional dengan } \\
\text { mengatasi masalah korupsi, kemiskinan, } \\
\text { dan kehancuran infrastruktur. }\end{array}$ & $\begin{array}{l}\text { DPR mengesahkan UU tentang LSM yang } \\
\text { melanggar hak kebebasan berserikat, } \\
\text { berekspresi, dan beragama; dengan } \\
\text { pembatasan ketat dana asing, dan larangan } \\
\text { LSM mendukung ateisme, Komunisme, } \\
\text { Marxisme-Leninisme. }\end{array}$ \\
\hline $\begin{array}{llr}\text { Reformasi } & \text { dan impunitas militer } \\
\text { ditunjukkan pengadilan militer yang } \\
\text { menjatuhkan hukuman penjara (antara } \\
\text { beberapa bulan sampai 11 tahun) terhadap } \\
12 \text { anggota Kopassus dalam serangan } \\
\text { pembunuhan atas 4 tahanan di LP } \\
\text { Cebongan İ Sleman, Yogyakarta. }\end{array}$ & $\begin{array}{l}\text { Kondisi di Papua di mana pasukan } \\
\text { keamanan menikmati impunitas atas } \\
\text { berbagai tindak pelanggaran, termasuk } \\
\text { penggunaan senjata berlebihan terhadap } \\
\text { pendukung kemerdekaan secara damai. } \\
\text { Sementara OPM bersenjata ï berjumlah } \\
\text { sedikit dan tidak terorganisirठ terus- } \\
\text { menerus melakukan serangan terhadap } \\
\text { pasukan pemerintah. }\end{array}$ \\
\hline $\begin{array}{l}\text { Hak-hak perempuan diakomodasi dalam } \\
\text { RUU kesetaraan gender yang diajukan ke } \\
\text { DPR tahun 2009, tetapi terhenti tahun } 2013 \\
\text { karena oposisi dari politisi Islam. }\end{array}$ & $\begin{array}{l}\text { Peraturan diskriminatif terus berkembang, } \\
\text { Komisi Perempuan melaporkan bahwa } \\
\text { pemerintah pusat dan daerah telah } \\
\text { mengesah-kan } 60 \text { peraturan baru yang } \\
\text { diskriminatif pada tahun 2013. Indonesia } \\
\text { memiliki total } 342 \text { peraturan diskriminatif, } \\
\text { termasuk } 79 \text { peraturan daerah yang } \\
\text { mewajibkan perempuan mengenakan } \\
\text { jilbab, larangan perempuan membonceng } \\
\text { mengangkang di Lhokseumawe, dan } \\
\text { larangan perempuan menari di Bireuen } \\
\text { Aceh. }\end{array}$ \\
\hline $\begin{array}{l}\text { Dalam hal kebebasan beragama Presiden } \\
\text { Yudhoyono berulang-kali menegaskan } \\
\text { bahwa Indonesia negara ñdemokrasi } \\
\text { Muslim moderatò, dan beliau tidak akan }\end{array}$ & $\begin{array}{l}\text { Pemerintah Yudhoyono gagal menegakkan } \\
\text { keputusan MA terhadap pejabat daerah } \\
\text { yang memblokir izin bangunan gereja- } \\
\text { gereja Kristen di Bogor dan Bekasi, }\end{array}$ \\
\hline
\end{tabular}


HUMANIKA Vol. 19 No. 1 (2014) ISSN 1412-9418

Menakar Penegakan Hak Asasi Manusia Di Indonesia

Slamet Subekti

\begin{tabular}{|c|c|}
\hline $\begin{array}{l}\text { mentolerir tindakan kekerasan tak } \\
\text { berperikemanusiaan yang dilakukan oleh } \\
\text { kelompok manapun yang mengatas- } \\
\text { namakan agama dengan } \\
\text { kekerasan. }\end{array}$ & $\begin{array}{l}\text { termasuk peraturan menteri tentang } \\
\text { pembangunan rumah ibadah dan keputusan } \\
\text { terhadap praktik keagamaan kaum } \\
\text { Ahmadiyah dan Syiah yang diskriminatif } \\
\text { dan mendorong berkembangnya } \\
\text { intoleransi. }\end{array}$ \\
\hline $\begin{array}{l}\text { Berkaitan dengan hak atas tanah, MK } \\
\text { menyatakan inkonstitusional ketentuan UU } \\
\text { Kehutanan Tahun } 1999 \text { yang memasukkan } \\
\text { wilayah adat ke dalam hutan negara. } \\
\text { Keputusan MK ini memerintahkan } \\
\text { Kementerian Kehutanan untuk } \\
\text { mengalokasi-kan lahan bagi masyarakat } \\
\text { sebagai konsesi dari penebangan hutan dan } \\
\text { perusahaan perkebunan. }\end{array}$ & $\begin{array}{l}\text { Korupsi dan salah kelola sektor kehutanan } \\
\text { melanjutkan kebocoran kas negara yang } \\
\text { mencapai kerugian US } \$ 2 \text { milyar per tahun, } \\
\text { jumlah ini lebih besar dari keseluruhan } \\
\text { anggaran kesehatan nasional. Salah kelola } \\
\text { hutan telah menimbulkan sengketa lahan } \\
\text { yang seringkali berujung pada kekerasan } \\
\text { ini membuyarkan klaim Indonesia sebagai } \\
\text { pemimpin dalam ñpembangunan hijauò } \\
\text { yang berkelanjutan. }\end{array}$ \\
\hline $\begin{array}{l}\text { Indonesia merupakan tempat transit ke } \\
\text { Australia bagi pengungsi dan pencari suaka } \\
\text { yang melarikan diri dari penganiayaan, } \\
\text { kekerasan, dan kemiskinan di negara- } \\
\text { negara termasuk Somalia, Afghanistan, } \\
\text { Pakistan, dan Birma. }\end{array}$ & $\begin{array}{l}\text { Keberadaan hampir } 10.000 \text { pengungsi dan } \\
\text { pencari suaka yang berada di Indonesia } \\
\text { pada Maret 2013, mereka tinggal di } \\
\text { penampungan dalam kondisi miskin dan } \\
\text { menderita. Sementara Indonesia tidak } \\
\text { memiliki hukum suaka, dan } \\
\text { mendelegasikan tanggung-jawab atas } \\
\text { pengungsi dan pencari suaka kepada } \\
\text { UNHCR. }\end{array}$ \\
\hline
\end{tabular}

Sumber: Human Rights Watch, World Report 2014: Events of 2013, New York. Dapat diakses pada www.hrw.org

Sehubungan dengan penegakan HAM di Indonesia, HRW merekomendasikan kepada Presiden Yudhoyono agar segera mengambil langkah nyata selama sisa masa pemerintahannya. Bagi seorang presiden bukan hal sulit untuk memastikan aparat hukum menindak tegas pelaku dan aktor intelektual di balik tindak kekerasan terhadap kelompok minoritas beragama. Pemerin-tah tidak perlu menunggu sampai pihak yang dirugikan mengajukan uji materi (judicial review) ke Mahkamah Agung atau Mahkamah Konstitusi. Disadari bahwa keberadaan berbagai peraturan diskriminatif itu jelas bertentangan dengan konstitusi negara UUD 1945, Undang Undang Perlindungan Hak Asasi, dan berbagai konvensi internasi-onal yang telah diratifikasi Indonesia.

\section{PERSEPSI MAHASISWA TENTANG HAM}

Survei lokal di kampus Universitas Diponegoro melibatkan 80 mahasiswa angkatan 2013/2014 Program Studi Pemanfaatan Sumber-daya Perikanan Fakultas Perikanan dan Ilmu Kelautan. Survei telah dilaksana-kan pada pertengahan Desember 2013. Berikut ini disajikan hasil survei tersebut.

\section{A. Dimensi Sipil dan Politik}

Responden mahasiswa memiliki persepsi positif hampir sebanding (56\%) dengan persepsi negatif (44\%) berkenaan dengan perlindungan hukum oleh Negara bagi semua warga negara. Lima puluh persen responden menyata-kan pernah 
mengalami perlakuan tidak adil secara hukum. Hanya sebagian kecil responden (26\%) merasa hidup dalam dunia yang bebas dan adil, sedangkan sebagian besar (68\%) tidak merasakan-nya. Menurut 59\% responden ada diskriminasi terhadap rakyat, sedangkan $29 \%$ menyatakan tidak ada diskriminasi.

Tingkat kepercayaan $46 \%$ responden besar bahwa di Negara kita ada demokrasi, sementara 29\% memiliki tingkat kepercayaan sedang, dan 25\% tingkat kepercayaannya kecil. Tingkat kebebasan berpendapat di Negara kita sedang menurut $60 \%$ responden, hanya $19 \%$ menyatakan rasa kepercayaan yang tinggi, dan $15 \%$ tingkat kepercayaannya rendah. Akses berbicara di publik berkaitan dengan persoalan warga negara relatif kecil menurut 54\% responden, 35\% berpendapat aksesnya besar, dan $11 \%$ menyatakan tidak ada akses sama sekali.

Lima puluh sembilan persen responden memberikan afirmasi bahwa semua orang sejak lahir memiliki kebebasan dan kesetaraan, sedangkan $37 \%$ tidak percaya. Bentuk perbudakan modern ada di Indonesia menurut $62 \%$ responden, $18 \%$ menyatakan tidak ada, dan $20 \%$ tidak tahu. Persepsi positif terungkap dari $25 \%$ responden terhadap kedudukan yang sama bagi setiap WNI di depan hukum, $60 \%$ bersikap skeptis, dan $15 \%$ tidak tahu.

\section{B. Dimensi Ekonomi, Sosial dan Budaya \\ Kualitas pendidikan di Indonesia} buruk menurut pandangan 58\% responden, $31 \%$ menyatakan kualitas sedang, dan $11 \%$ menganggap kualitas pendidikan baik. Krisis ekonomi berpengaruh terhadap pelayanan sosial dari Negara menurut 60\% responden, sementara $25 \%$ menganggap tidak berpengaruh, dan $15 \%$ menyatakan tidak berpengaruh sama sekali. Perlindungan masyarakat terhadap anak menurut $65 \%$ responden adalah sedang, $20 \%$ menyatakan perlindungan baik, dan 10\% menganggap perlindungan anak buruk.

Sensitivitas masyarakat besar terhadap pelecehan perempuan menurut $47 \%$ responden, $43 \%$ menyatakan sensitivitas masyarakat kecil, dan $10 \%$ menganggap tidak ada sensitivitas sama sekali. Hampir seperempat dari total responden $(23 \%)$ menyatakan mereka pernah mengalami kekerasan dalam rumah tangga, $42 \%$ tidak mengalami, dan $35 \%$ responden tidak mau menjawab. Menurut 59\% responden bahwa pencipta lagu berhak atas keuntungan dari hak cipta lagunya, tetapi $21 \%$ menyatakan tidak berhak, dan $21 \%$ responden tidak memberikan jawaban.

Tigapuluh dua persen responden menyatakan pernah mengunduh secara ilegal lagu atau film dari Internet, 53\% kadang-kadang melakukan, dan $15 \%$ menyatakan tidak pernah. Lelaki dan perempuan digaji sama besarnya untuk pekerjaan yang sama disetujui $60 \%$ responden, sedangkan $30 \%$ tidak setuju, dan $10 \%$ tidak memberikan jawaban. Seandainya menjadi pengusaha $48 \%$ responden menyatakan tidak akan mengambil keuntungan dari karyawan untuk memperoleh uang yang lebih banyak, sementara $35 \%$ akan mengambil keuntungan, dan $17 \%$ tidak memberikan jawaban.

\section{Dimensi Solidaritas}

Menurut 50\% responden bahwa Negara perlu memberikan suaka bagi pengungsi, sementara $25 \%$ menyatakan tidak perlu, dan $25 \%$ menjawab bergantung situasinya. Pengungsi dan imigran harus diberi kewarganegaraan Indonesia menurut pandangan 29\% responden, sementara $63 \%$ bergantung situasi, dan $8 \%$ menganggap tidak perlu. Duapuluh sembilan persen responden memiliki tingkat kepercayaan yang besar bahwa warga Negara bertanggung-jawab kepada masyarakat dan negara, 61\% tingkat kepercayaannya kecil, dan 10\% responden tidak percaya sama sekali. 
HUMANIKA Vol. 19 No. 1 (2014) ISSN 1412-9418

Menakar Penegakan Hak Asasi Manusia Di Indonesia

Slamet Subekti

Warga Negara berhak mempertahankan hak-haknya menurut $80 \%$ responden, sedangkan $20 \%$ mengatakan tidak. Duapuluh sembilan persen responden merasa bebas untuk pindah ke negara lain, tetapi 59\% merasa tidak bebas, dan $12 \%$ tidak memberikan jawaban. Pendidikan menjadi faktor penting untuk melestarikan perdamaian diafirmasi $73 \%$ responden, sementara $22 \%$ menegasikan, dan $5 \%$ responden tidak tahu.

Peningkatan jumlah mahasiswa asing menjadi masalah menurut persepsi $12 \%$ responden, $50 \%$ menyatakan tidak masalah, dan 38\% menganggap sedikit masalah. Keberadaan mahasiswa asing berdampak negatif terhadap pendidikan mahasiswa Indonesia menurut 12\% responden, tetapi $50 \%$ menyatakan tidak berdampak negatif, dan $38 \%$ menganggap sedikit berdampak negatif. Kehidupan, kebebasan, dan keamanan personal para imigran menurut 54\% responden dilindungi di Indonesia, 25\% mengatakan tidak dilindungi, dan $21 \%$ responden tidak tahu.

\section{Catatan Kritis}

Selama ini pembicaraan tentang HAM menyisakan aspek kontroversial dalam dua isu utama. Isu pertama bernada gugatan terhadap sifat universal HAM, bukankah wacana HAM berasal dari Barat dan tidak dapat serta-merta ditransfer ke dalam kebudayaan lain? Kiranya benar bahwa perkembangan dan penyebarluasan wacana HAM berkem-bang dalam budaya dan tradisi Barat. Akan tetapi, benar juga merupakan sifat dasar seseorang tidak mau diperlakukan diskriminatif karena agama atau warna kulitnya itu bersifat universal (Barkemeyer dan Kunzi, 2011).

Diakui bersama bahwa setiap warga negara menginginkan dapat membicarakan opininya tanpa rasa kuatir, dan semua orang mendambakan hidup bermartabat tanpa menderita kelaparan. Jadi, jelas bahwa semua ide yang tercakup dalam pengertian HAM ini bersifat universal. Penting dicatat bahwa seringkali negara-negara maupun berbagai kelompok yang bertanggung-jawab terhadap pelanggaran HAM lazim menggugat sifat universalitas HAM tersebut.

Isu kedua berkaitan dengan kasus di mana negara-negara Barat mengusung isu HAM untuk membenarkan intervensi militer ke negara-negara lain. Keberatan terhadap intervensi militer tersebut, karena tindakan itu merupakan pelanggaran HAM terhadap kedaulatan suatu negara. Jelas tidak satu pun negara pembela HAM membenarkan tindak pembalasan pelanggaran HAM negaranegara Barat dengan melakukan tindak serangan 11 September misalnya, sehingga diperlukan kesepahaman dalam kerangka HAM untuk menjustifikasi tindakan perang melawan terorisme.

Sehubungan dengan itu, pendidikan HAM berperan penting dalam rangka mengembangkan karakter pembelajar dalam kemampuan nilai kebebasan pemikiran, kesadaran dan keyakinan; kemampuan dalam nilai kesetaraan, keadilan dan cinta; serta kemauan untuk peduli kepada sesama dan melindungi hak-hak anak, perempuan, pekerja, kelompok minoritas, dan sebagainya (UNESCO, 1998). Dalam konteks Indonesia, pembelajaran HAM dalam matakuliah Pendidikan Pancasila dan Kewarganegaraan berperan mendukung pengembangan karakter siswa (termasuk mahasiswa) berkepribadian Indonesia dan responsif dalam tata pergaulan dunia. Perjuangan untuk menegakkan HAM mesti terus-menerus diperbarui sesuai dengan dinamika perkembangan nasional dan internasional dalam rangka mengawal perdamaian dunia. 


\section{SIMPULAN}

Hak Asasi Manusia bersifat universal dan perlu dibudayakan melalui pendidikan dalam rangka pengembangan karakter siswa dan mahasiswa berkepribadian Indonesia dan responsif dengan lingkungan global. Hasil survei baik skala nasional maupun internasi-onal menyimpulkan bahwa penegakan HAM di Indonesia dewasa ini cenderung menurun disebabkan kinerja lembaga-lembaga HAM tidak optimal dan pemerintah dinilai gagal menindak tegas pelanggaran HAM, oleh karena itu direkomendasikan kepada Presiden agar mengambil langkah nyata dalam penin-dakan terhadap pelanggaran HAM serta penghapusan undang-undang maupun peraturan daerah yang diskriminatif di Indonesia. Survei lokal di kalangan mahasiswa menunjukkan respon positif terhadap pelaksanaan HAM dalam dimensi sipil dan politik, ekonomi, sosial dan budaya, serta dimensi solidaritas; dan merespon negatif terhadap pelanggarannya. Akhirnya, di-sadari bahwa penegakan HAM bersifat wajib dengan respek kepada semua individu, dan perlindungan HAM men-jadi pusat kegiatan pemerintahan demi mewujudkan keadilan sosial bagi seluruh rakyat Indonesia dan meraih cita-cita perdamaian dunia.

\section{DAFTAR PUSTAKA}

Barkemeyer, Jorn \& Jan Kunzi. (2011). Human Rights. Video proyek Wissens Werte. Dapat diakses pada http://www.edeos.org

Hendardi, Bonar Tigor Naipospos \& Ismail Hasani. (2013). Indeks Kinerja Hak Asasi Manusia (IKH) 2013. Jakarta: SETARA Institute. Dapat diakses pada http://www.setarainstitute.org/en/content/indekskinerja-hak-asasi-manusia-ikh-2013

ñHuman Rights Watch: Penegakan HAM di Indonesia Mundur Jauh ke Belakangò. Tempo digital edisi 2 Februari 2014. Dapat diakses pada http://pediakita.com/human-rightswatch-penegakan-ham-diindonesia-mundur-jauh-kebelakang.html

Human Rights Watch. World Report 2014: Events of 2013. Hassan Elmasry (the Board of Director), New York: Seven Stories Press. ISSN-13: $\quad$ 978-1-60980-555-5 Dapat diakses pada www.hrw.org

Mahbub, Amri. ñKinerja Institusi HAM di Indonesia Turunò. Tempo digital edisi 9 Desember 2013. Dapat diakses pada http://www.tempo.co/read/news/20 13/12/09/078535887/KinerjaHAM-Indonesia-Turun

Undang Undang Dasar Negara Republik Indonesia 1945 dan Amandemennya, Cetakan Pertama, November 2004. Bandung: Fokusmedia.

UNESCO (1998). Learning to Live Together in Peace and Harmony: Values Education for Peace, Human Rights, Democracy and Sustainable Development for the Asia-Pacific Region. Bangkok: UNESCO Principal Region Office for Asia Pacific.

\section{Ucapan Terimakasih}

Penulis mengucapkan terimakasih kepada para mahasiswa angkatan 2013/2014 Program Studi Pemanfaatan Sumberdaya Perikanan, Fakultas Perikanan dan Ilmu Kelautan Universitas Diponegoro Ï meliputi kelas A di bawah koordinasi Lucy Pratitis Sejati (NIM 26010313120028) dan kelas B di bawah koordinasi Andika Wiratama (NIM 26010313140084)ठ yang telah berpartisipasi menjadi responden survei Penegakan HAM di Indonesia (Desember 2013 
Lampiran 1. Respon Mahasiswa Angkatan 2013/2014 Prodi PSP, FPIK Universitas Diponegoro terhadap Survei Penegakan Hak Asasi Manusia di Indonesia

No

Pernyataan

1. Usia

2. Jenis kelamin

\section{Dimensi Sipil \& Politik}

3. Apakah semua orang dilindungi oleh hukum?

4. Pernahkah anda diperlakukan tidak adil secara hukum?

5. Apakan anda merasa hidup dalam dunia yang bebas dan adil?

6. Apakah anda percaya bahwa tidak ada diskriminasi terhadap rakyat?

7. Seberapa besar anda percaya bahwa di Negara kita ada demokrasi?

8. Menurut anda seberapa tingkat Ting kebebasan berpendapat di Negara kita?

9. Seberapa besar akses berbicara di publik berkaitan dengan persoalan anda?

10. Percayakan anda bahwa semua orang sejak lahir memiliki kebebasan dan kesetaraan?

11. Menurut anda, apakah bentuk perbudakan modern ada di Indonesia?

12. Apakah setiap warga Negara Indonesia memiliki kedudukan sama di depan hukum?

\section{Dimensi Ekonomi, Sosial \&} Budaya

13. Bagaimana kualitas pendidikan di Indonesia?

14. Apakah krisis ekonomi berpengaruh terhadap pelayanan sosial dari Negara?

15. Bagaimana perlindungan masyarakat terhadap anak

16. Seberapa masyarakat sensitif terhadap pelecehan perempuan?
[\%]

13-15

Perempu [56]

Ya

Ya

Ya

Ya

[29] Tidak

Besar

[46]

[56] Tidak

[50] Tidak

[26] Tidak

[\%]

[\%]

[20] $18-21 \quad$ [80]

[44] --

[44]

[50]

[68] tidak punya

jawaban [6]

[59] tidak tahu

[29] Kecil [25]

Besar

[35] kecil

[54] tak ada [11]

Ya

[59] Tidak

[37] Tak tahu [4]

Ya

[62] Tidak [18]

Tidak tahu

Ya

$[25$

Mungkin

[60]

Tidak tahu

[15]

\begin{tabular}{|c|c|c|c|c|}
\hline Baik & [11] & sedang & [31] & buruk [58] \\
\hline Ber & $\begin{array}{l}\text { aruh } \\
\text { [60] }\end{array}$ & Tidak & [25] & $\begin{array}{l}\text { Tidak sama } \\
\text { sekali [15] }\end{array}$ \\
\hline Baik & [20] & sedang & [65] & buruk \\
\hline Besar & [47] & kecil & [43] & $\begin{array}{l}\text { tidak sama } \\
\text { sekali } \quad[10]\end{array}$ \\
\hline
\end{tabular}


17. Pernahkah anda mengalami

kekerasan dalam rumah tangga?

Ya $\quad[23]$

[42] Tidak jawab

Ya

[59] Tidak

[21] Tidak jawab atas keuntungan dari hak cipta lagunya?

19. Apakah anda mengunduh secara

Selalu

[32] Kadang

[53] Tidakpernah ilegal lagu atau film dari Internet?

20. Apakah lelaki dan perempuan

Ya

[60] Tidak

[30] Tidak jawab digaji sama besarnya untuk pekerjaan yang sama?

21. Seandainya anda pengusaha akankah mengambil keuntungan Ya

[35] Tidak

[48] Tidak jawab dari karyawan untuk memperoleh uang yang lebih banyak?

\section{Dimensi Kelompok}

22. Perlukan kita memberikan suak bagi pengungsi?

Haruskah pengungsi dan imigran

Ya

[50] Tidak

[25] Tergantung

23. diberikan kewarganegaraan

Ya, semua di-

Ya, tergantung

[25] Indonesia?

beri [29] situasi [63]

24. Seberapa besar anda percaya

Besar [29] Kecil

[61] tidak sama akan warga Negara bertanggungjawab pada masyarakat dan negara?

25. Apakah warga Negara mempertahankan hak-haknya?

26. Apakah anda merasa bebas untuk pindah ke negara lain?

27. Apakah pendidikan menjadi faktor penting untuk melestarikan perdamaian?

28. Apakah peningkatan jumlah mahasiswa asing menjadi masalah bagi anda?

29. Apakah keberadaan mahasiswa asing berdampak negatif terhadap pendidikan mahasiswa Indonesia?

30. Apakah kehidupan, kebebasan, dan keamanan personal para imigran dilindungi di Indonesia?

$\begin{array}{llllr}\text { Ya } & {[80]} & \text { Tidak } & {[20]} & -- \\ \text { Ya } & {[29]} & \text { Tidak } & {[59]} & \begin{array}{r}\text { Tidak jawab } \\ {[12]}\end{array} \\ \text { Ya } & {[73]} & \text { Tidak } & {[22]} & \begin{array}{r}\text { Tidak tahu } \\ {[5]}\end{array} \\ \text { Besar } & {[21]} & \text { kecil } & {[45]} & \begin{array}{r}\text { tidak sama } \\ \text { sekali } \quad[34]\end{array} \\ \text { Ya } & {[12]} & \text { Tidak } & {[50]} & \text { sedikit [38] } \\ \text { Ya } & & & & \\ \text { Y54] } & \text { Tidak } & {[25]} & \text { Tidak tahu }\end{array}$

Ya

[54] Tidak

Catatan: $\quad \mathrm{N}=80$ 